\title{
The Image of China of the Spanish Cultural Context:-Take Borges' Novels as an Example
}

\author{
Wang Zi \\ Spanish Department of College of Foreign Languages, Jilin University, Changchun City, China
}

\section{Email address:}

46315677@qq.com

\section{To cite this article:}

Wang Zi. The Image of China of the Spanish Cultural Context:-Take Borges' Novels as an Example. Humanities and Social Sciences. Vol. 5, No. 2, 2017, pp. 97-101. doi: 10.11648/j.hss.20170502.18

Received: March 19, 2017; Accepted: April 22, 2017; Published: May 4, 2017

\begin{abstract}
Spanish is widely used around the world. With the development of globalization, the two cultures between Spain and China have intersected a lot. In Spanish literature, more and more works show the image of China. The works of Argentine writer Borges have a lot of descriptions about China, which portray a series of image of China. The writer Borges himself grows under Spanish culture, meanwhile, he is also familiar with Chinese culture, too. Therefore, the author hopes that through the study of the image of China in the works of Borges, we can conclude effective experiences, which can be applied to the appreciation of image of China in the works of Spanish native writers, but also can develop our own image of China.
\end{abstract}

Keywords: Spanish Literature, Borges, Image of China

\section{Introduction}

For a long time, the study of image of China in foreign literature is a key issue in the field of comparative literature. In recent years, the related academic achievements in China have came a lot, but the objects of study still only concentrate on the literary works about some representative countries, such as the United States, Britain, and France. And the discussions of image of China created by the literary works in other languages are very few with little results.

The national image is of a country's external and internal stability relative to the country's overall public awareness and comprehensive evaluation. The national image of a country is decided in the country's own development and the international community values, cultural consciousness, the behavior standards and so on. International communication's final goal is the construct our actual country image, and its objective is "let the world understand China, let the Chinese understand world".

Spanish literature is typical. Spanish, as the main language used in Latin America is one of the five common office languages, and the cultural intercourse between Spain and China is not interrupted. It is also common that China being described appears in the Spanish literature. Therefore, it is necessary to study image of China in the literary works of the Spanish cultural context, which not only enriches and develops the comparative literary image, but is also conducive for us to understand image of China under foreign culture, and provide the basis for our country to develop a more scientific and rational foreign policy in the future. Therefore, the author chooses the famous writer Borges of Argentina as the main object of analysis, exploring its relationship with Chinese culture and its literary works in shaping image of China. Wang $\mathrm{Xi}$ mentioned in The Chinese Complex of Borges that he had said to Huang Zhiliang who was the Chinese diplomat of Argentina coming to visit him in 1982: "I told many people that I have dreamed a lot of time to go to China. " Because of his physical reasons, he did not fulfill his desire, but many of Borges' works are related to the Chinese theme, which can show the strong Chinese complex of a foreign writer.[1]Taking Borges' works as an example, the reason is that as a representative writer in Latin America, his works not only have a strong literary nature, but also reflects the mutual exchanges and mutual influences between Spanish culture and post-colonial culture, and it has value to discuss.

\section{Borges and China}

\subsection{The Introduction About Borges}

Argentinean writer Jorge Luis Borges (Jorge Luxuis $1899-1986)$ is a pioneer of the "literary explosion" in Latin 
America. Many world-renowned writers have a high opinion of Borges, and Chile's great poet Pablo Neruda calls him "the first Latin American writer to influence European and American literature." Writer Serra said, "Borges is a magician infinite alchemist, he created the world with numerous people and cities." Peruvian famous writer Mario Vargas Lausa also has a higher rating on Borges, he said: "Borges is not only the world's greatest literary master, but also an extraordinary master of creation. Because of Borges, we have won the international reputation of Latin American literature. He broke the traditional bondage, and put the prose to a very noble realm. This is a man with stunning imagination, outstanding cultural literacy, driving a simple, concise, accurate text of the literary star. "Borges in the field of world literature has also been recognized by many critics," the famous American literary critic John Brahim Wood said, A study of American literature scholars of American literature is divided into two periods: before Borges and after Borges. I think this is reasonable." Thus, we can see that Borges has a deep impact of world literature. In Western Canon, Borges was ranked as the 26th influential world literature master. So the study of his work is important for every study of the world's literary workers. With such a literary achievements and a profound impact on world literature, he has a close relationship with China. Not only Borges himself loves Chinese culture, but also has a strong desire for China. In his works, the image of China is the most successful foreign image of its creation, and adds a lot of charm to his work.

Before discussing the relationship between Borges and Chinese culture, we first look at the growth and creation of Borges. Borges has received a high education since he was young. His father has a large number of books, and his grandmother is an English, so Borges can master Spanish and English, which helps him to read a large number of Chinese and foreign literature. And Borges' understanding of China is also from the English translation. His mother also loves literature, and she became the first reader of Borges. Growing up under such a strong literary atmosphere, he has shown an extraordinary literary talent. When he was nine years old, he translated Wilde's Happy Prince, and also translated into Spanish and published on El Pais in Buenos Aires. Borges' first book, "The Passion of Buenos Aires", was published in 1923, and since then to 1986 , he died. He has created more than 30 works in his life. Among them, the first novel in 1935 has given him a lot of fame, The Villain Biography, and Female Pirates Gold Widow is directly based on ancient Chinese folklore. The unique writing style of his works immediately aroused the attention of many literary critics. The publication of the Boulevard Bifurcated Garden in 1944 gave Borges a greater impact around the world. Western countries began to pay attention on Borges and study his work from the fifties, it has continued until today and has never been interrupted. In Europe and the America, there are about a thousand books talked about Borges' theory and commentary, and even many scholars have been awarded with the National and International Awards for studying Borges.

\subsection{Borges and the Chinese Culture}

Borges and China have a very close contact which committed to the mutual influence. First of all, Borges' writing style has been deeply influenced to the writers of the eighties and nineties in China, such as Yu Hua, Ma Yuan, GeFei and other writers of the Chinese literary circles in the new period. So Borges is known as "the writer of the write". Second, which is more important, the Chinese elements in the works of Borges are the main objects of their description and expression. The author will also focus on the content of the discussion.

Personally, Borges is very fond of the Chinese traditional culture, and has been deeply influenced by the Book of Changes, Zhuangzi, Tao, The Dream of Red Mansions, Water Margin, Strange Stories and other Chinese classical class. In the works of Chinese elements appeared in a variety of ways, such as The Female Pirates Gold Widow, The Garden of Forking Paths, the two novels are directly to the Chinese culture as the theme, or in the process of citing the Chinese classical books, or the comment on the Chinese classical novels, or expressing their feelings, such as the poem the Paint Cane. According to some scholars statistics, the converging of Borges' works related to China and the Chinese culture was 37 points as much. He also has repeatedly expressed the fascination of China, not only in the works we can appreciate this enthusiasm, but also in his life, Borges also do not cover up his emotion. In the The Great Wall and the Book, China as a theme of a philosophical prose, Borges once said: "What a great pity if $i$ haven't been to China. The Great Wall, I must get here." The Chinese scholars Huang Zhiliang, interviewed him in 1981, he had said, "... I have been blind, but I can feel it, and I will touch the magnificent masonry by hand." [2]Although Borges did not come to China in his lifetime, but his enthusiasm for China is true.

Borges' feelings and impressions on China are indirect, which are all from reading books. In his father's small library, Borges read a lot of books that has a lot of descriptions of the Oriental, books are in English translation version. Under the action of this indirect way, in the eyes of Borges, the Oriental was gradually growing into a mysterious existence.

\subsection{The Chinese Elements in Borges'Works}

After careful studying and screening, summing up the Borges' works of the image of China are: The Female Pirate Gold Widow, The Garden of Forking Paths, Tron, Ukbar, Orbis, The Story of Samurai and Prisoners, Aveiro's Exploration and Zaire. These novels with Chinese elements are distributed in the Borges' novels, The Devil Biography (1935), The Fictional Set (1944) and Alev (1949). In these novels, some of the images of China are existed with the short vocabulary, some are created through the entire chapter, writing a variety of forms and content covering all aspects of life. All these words constitute the images of China of Borges' works. In many chapters, The Female Pirate Gold Widow and The Garden of Forking Pathsare the strongest correlations with the Chinese elements of the two novels. Therefore, the author mainly to these two novels as an example to describe 
the Borges-style Chinese image, which show the mysterious image of China's other types of works.

The Female Pirate Gold Widow is the only one work which involving a lot of the Chinese elements of Borges and the only novel that uses purely Chinese characters of traditional Chinese literature. Although Borges in his works references to China a lot while most of his describing was overhead, but with the form of the image of China only. So in the The Female Pirate Gold Widow, the story and the characters are only based on his own understanding of the Oriental culture. The novel tells the story of the woman's pirate gold widow's heroic impression when she fought against Imperial Navy, but in the face of the emperor Jiaqing emperor envoys, she can't help herself but thinking of the dragon and fox fable, so she surrendered to the court. This story plot was the same with the Chinese classic novel: Liang Shanbo command Song Jiang was amnesty. In this works, Borges described the widow's image is comprehensive, there are many descriptions of direct appearance, such as "slim, chiseled and narrowed his eyes, when she smiles decay", through comparing with the different countries, they also have the image of female pirates. The author introduced the pirate who was under the growth of the Western culture at the beginning of the article, they are brave as a man who is generally like "a real man". Borges is so carefully that he arranged to compare the two types of female pirates on their own purpose. In the image in the text, when the positioning of the organization and the level of principle existed, people will pay attention to the dividing line between me and the others. [3]Therefore, the difference between the female widow and the female pirates in the Western world is the unique image of the golden widow who wants to emphasize. Although the golden widow did not fight like a real man, but she was good at using the wise to win. After the death of her husband, she controlled the overall situation when she got leadership. It was almost the same case that happened in China, in the Chinese history, the young Empress Dowager Cixi gets the conspiracy from the hands of the ministers after the collapse of the Emperor. Gold widows also have the organizational skills which forced her to formulate many rules and regulations and have the capability to make court decisions.

Compared with the The Female Pirate Gold Widow, the story plot of The Small Bifurcated Garden story was more complex which connotation and the interpretation were more wealthy. The novel took place in the background of the British and German war, the protagonist -Yu Zhun, a Chinese, was sent to the British army as a spy. In order to prove the ability to Germans, he decided to carry out a special task, because the information was so important that can' $t$ be passed out, which forced him to kill an innocent person - Albert. Albert, who was innocence, was a sinologist and had a great relationship with Yu Zhun. Albert deciphered the unfinished work of Yu Zhun's grandfather's-The Small Bifurcated Garden. A lot of Chinese classical books were found in Albert's residence, which shocked Yu Zhun and greeted Albert with eagerness. But this did not stop Yu Zhun killing Albert, so when the British detective-Ma Deng arrive, Yu Zhun did not hesitate to kill the person who was the best understanding of his grandfather- the British Sinologist, Albert. A large number of the descriptions of the characters and the introduction of Chinese books can explain Borges' love of the Chinese culture.

In addition to The Female Pirate Gold Widow and The Small Bifurcated Garden, the essay The Great Wall and the book also fully demonstrated the author of the mysterious world interpretation of the Oriental. The Great Wall and the book can be said that Borges in reading the Qin Shihuang built the Great Wall and burned book Kengru and other related stories after reading the sense of the emperor's palace complex, such as the maze that also shows that in the eyes of Borges, Chinese is an ineffable maze. In the poem, The Paint Cane, Borges, who was from the black paint, can't leave the body which thinks of the China's Great Wall and Zhuang Zhou's dream that referring to the butterfly's story. Although the image of China is only a few simple images of the writer that built up, but Borges fully expressed his longing for China.

The shaping of the image of China is an important part of the Borges literary world, and the literary style of his works is also manifested through the construction of the image of China. From this, Borges' feeling for China is evident. But the writer himself did not come into contact with the Chinese culture, but only through the translation of books to understand the Oriental, so he built the image of China and the real reality of China far worse. In fact, this is a Chinese cultural symbols to express Western cultural content of the image of China. So the image of China in Borges' literary world will show the unique characteristics.

\section{The Characteristics of Chinese Literary Image in Borges' s Works}

\subsection{The Passivity in Image of China}

Borges understands China through the description of the text. It may strengthen China's mysterious color, but also divides the Borges' literature works in China and the reality of China's characteristics. In the literary works, he deals the Chinese elements in the way of "Self-regardless". $\mathrm{He}$ reassembles the Chinese cultural symbols in order to maintain the purpose of forming a new image, which is to show the culture and thought of Borges himself. Hence, in the process of being described, China approaches to the passive stage. The shape of the image of China is the means of the writer rather than the purpose he wants to express. But in Borges' works, this passivity is more prominent, and China even lost the opportunity to voice for herself.

In the small bifurcated garden, the British sinologist can interpret the main character's profound meaning. The main actor, who is Chinese, not only can't understand the words written by his grandfather, but also actively proves himself to the Germans. This shows that in the mind of Borges, the Western culture still dominate the whole world, while China is just a follower. Although Borges has always believed that the ancient Chinese culture represented by China is mysterious and profound, the East people can't correctly interpret the 
ancient oriental culture, and only the developed Western world can explore the value of Oriental culture and its profound significance. So Borges thinks that China does not have the ability to explain their own value, it needs the help of Western countries.

Borges has a strong feeling for China. However, the status of his own culture and the description of the Chinese culture is not equal. In his mind, the Western culture represented the truth, and is the symbol of civilization, but the Oriental world is just a pile of material waiting for analysis passively. As Borges said, "Our tradition is all Western culture, and we have the right to have this tradition, more than any other inhabitant or country." Borges is consciously closer to the Western culture, and performs in western way. [4]In this sense, Borges stands in the perspective of the Western way. We can see that when the Western world feels confused and panic in the spiritual field, they look forward to find the sustenance and comfort in heart to the mysterious oriental world with their own sense of superiority. In The Cultural similarity and usage, Shi Jingqian said:" that most of the writers I have talked about start to study China when they feel that their own cultural future is uncertain. For those Westerners who are insecure and the anxious, in some extent, China has become their way out or retreat.'[5]

\subsection{The Pattern in the Image of China}

In most of Borges' works, there are a lot of Chinese elements, but the image consisted of these Chinese cultural elements is in certain pattern. There are two main reasons can explain this characteristic.

First of all, in the history of western literature, the image of China is characterized by two extreme tendencies. On the one hand, it is a collection of all good words, on the other hand it represents the worst. The image of China is always in the two fixed state, idealism and demonized. In the text of the western world, the image of China was portrayed as an ideal incarnation before the European Industrial Revolution. In many works, the western people thought the oriental world is the collection of rights and money with mystery. At that time, the West received the information about the Oriental only by the missionary travel. Most of the missionaries traveled to the Eastern Empire and received a grand reception for its harmony and prosperity. Then, they returned back with these notions. At the same time, in order to inspire their own nation to visit the Oriental, some missionaries used exaggerate descriptions about the Empires. The opening of the new route opened the era of geographical discovery. Afterwards, the western world took the lead in carrying out The Industrial Revolution, and the Oriental countries dominated by agriculture were far behind the western countries. Under such situation, western countries began to have the opportunity to personally contact with this mysterious oriental world, and China as its representative began to slow down from westerners' perspective. The image of China has been changed from being idealistic to being stupid, greedy and even demonized. According to this, the image of China has the model and pattern. Secondly, Borges himself also uses confirmed words to describe the image of China. This is the reason why his works are full of such characteristics. For example, from the facet of the display of Chinese gardens, in Boulevard Bifurcated Garden, Borges used the description to provide a real scene of the Chinese garden for its narrative. More importantly, by describing the complex structure of the garden highlights that China has been fixed of the mysterious image. In the aspect of character setting, Borges continued to use the ideological tradition of the late Western world, and the Chinese characters in the works generally appeared as "villains". For example, the golden widow is a female pirate, and Yu Zhun is a spy who kills his grandfather to complete the task without any hesitation.

For a long time, the image of China in western literature has a fixed pattern about characteristics, and the relationships between Borges and China is very complicated, so in his works the image of China appears in a flat way than richness.

\subsection{The Marginalized Development Trend of Image of China as "Other Image"}

In Borges' works, we can clearly feel the author's passion and yearning for Chinese culture. However, such flat image can't stands for the real image of China. Owing to this, the image of China, which has been described from a western perspective, has been gradually marginalized.

Borges is a writer of Latin America. As for the western world, Argentina is also on the edge of western culture. Compared with western culture, the relation between Argentina and the eastern culture is closer, but Borges is more willing to integrate themselves into the western world, consciously standing from the position of western culture to describe the image of china. In the traditional world order, the first world have stronger advantages in the political and economic areas, so they have more power to dominate in the field of culture which makes the developing countries continue to move towards the direction of marginalization. With the trend of economic globalization, many developing countries is in a dilemma, whether they are actively involved in the fierce competition of the globalization or not. The version of Borges about global development is not only an active participation in the process of globalization, but also the acknowledgment about the cultural position of the western world. Borges' works have been recognized and praised by the whole world indeed. The main reason for this is that the values he chooses are from the western world which dominate values the world. Under the guidance of such ideology, combined with Borges' unilateral understanding of the realities of Chinese culture, cause the image of China in his work is full of passive characteristics. We can find that Borges consciously chooses to describe China from the western cultural perspective shows that his own culture changes its way to develop. The real aim to describe others is to express themselves. Borges argues that it is only possible to eliminate the marginalization of the writer's own culture by recognizing that China has a marginalized feature compared to the western countries. Generally speaking, China as a foreign image, which marginalized trend has been further strengthened in this 
process.

In conclusion, we should understand that under the irresistible development of globalization, China should take the initiative to participate in this competition, and shape their own image actively. We can't accept the fixed image from other countries, and should accept the idea to cooperate with them.

\section{Conclusion}

In China, the study of image of China in Spanish culture is less in the field of comparative literature. However, with the intersection between Chinese and Spanish culture, more and more image of China appear in Spanish literature. So it is necessary to study the image of China of the Spanish cultural context. Through the consideration and combing of the image of China in Borges' works, we can summarize valuable experiences and apply them to comment and analysis other Spanish works. At the same time, we can compare different characteristics of image of China in Spanish by different regions and times. There are many descriptions about image of China in some contemporary works in Spain, indicating the practicability of such research. With the continuous development of China, more and more Chinese go abroad, and many of them choose to emigrate to Spain. And we should consider the relationship between Spanish and Chinese. Spanish have formed their own judgments in this process of getting along with Chinese. This impression will be reflected in the literary creation, and also impacts the development of diplomatic policies among countries and ethnic exchanges. The Chinese Shadows: Analysis about Chinese Impression in Spain mentions:" The Chinese in Spain do not get trusted like the Latin American people but they still have something good than Moroccan. And we always stress that Chinese ought to integrate into our culture indeed." Chinese immigrants in Spain is truly a special group, and the evaluation and judgment of this special groups will performance in the field of ideas. Therefore, in this new era, the exploration of the image of China in Spanish literature is worthwhile.

The Argentine writer Borges is a well-known writer. Although he loves China, his version of image of China is from single perspective, and the characteristics in his works is passive and in pattern. At the same time, Borges himself is influenced by western culture when he was young, and agrees with its values. All of these cut the trend of marginalization, and make the image of China far from the center to speak. Faced with this reality, we should not only make effort to study the characteristics about image of China in foreign literature as much as possible, but also sum up experiences trying to take the initiative to build our own image.

\section{References}

[1] Wang Xi The Chinese Complex of Borges [J]. The World Culture, 11: 18-19,2008.
[2] Can Xue, interpretation of Borges (M) in Beijing, the People's Literature Publishing House.

[3] [French] Daniel - Henry Barou: From the cultural image to the collective imagination MengHua translation, quoted from MengHua editor: The Comparative Literature Image, Peking University Press, 2001 edition, page 136th.

[4] Zhao Shixin Borges and Chinese Culture [D]. Tianjin: Tianjin Normal University.2008.

[5] Shi Jingqian Cultural similarity and usage [M] Beijing: Peking University Press. 1990.

[6] Yang Xiaolian, Ding Wei, Peng Xi "Other Image" in the Post-colonial Context - On the Image of China in Borges [J]. Journal of Chongqing University of Technology (Social Science), 2011,10: 98-102.

[7] Chen LinqunBorges in Maze [J]. Bookstore, 2000,04: 64-67.

[8] Huang YueThe Western "Imagination" in Chinese "Symbol": A Comparative Study of "The Great Wall of China" and "The Great Wall and the Book" [J]. Journal of Suzhou Education University, 2012,03: 43-46.

[9] Xiao Fan Different world: The Borges Study of Image of China [J]. Writers.2012, (22): 66-67.

[10] Jia Zhongshan, Zhu Wanjun. Analysis of the Chinese national image in the three newspapers of the Spanish media - Taking the report of China during the "18th National Congress of the $C P C^{\prime \prime}[\mathrm{J}]$. Journalism and Communication Studies, 2013,04.

[11] NOURIEL ROUBINI. A return to 2008[N]. El Pais, 2016-03-07.

[12] RAMON AYMERIC. Storm in the markets: El sindrome de China [N]. La Vanguardia, 2015-08-25.

[13] Sun Yijun, Ge Zhihong.Discussion on the Ethical Dilemma and Construction Principles of Cross-cultural Communication in the Context of New Media [J]. Modern Communication, 2013(10).

[14] Sun Youzhong. The connotation and function of the national image [J]. International Forum, 2002 (3).

[15] Cai Qian. The Chinese Image in Borges's Novels [D]. 2010.

[16] Manuel Bayo.China in the Hispanic literature. 2013.

\section{Biography}

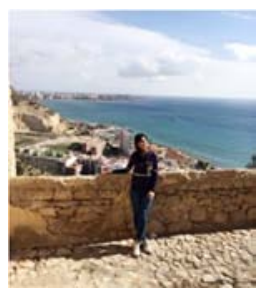

Wang Zi, who is born in August 10, 1986 in Changchun City, Jilin Province, is han. She works as a lecturer in the Spanish Department of College of Foreign Languages of Jilin University. In 2012, she received a master's degree in Spanish and since then, she has been working as a lecturer in Jilin University until now. At present, she studies for a doctor's degree at the University of León in Spain, whose main research direction is Spanish Literature. 